\title{
LA ViolenCia INTRAFAMILIAR en Cartagena: \\ Un Asunto de Mentalidades*
}

\author{
Por: Hortensia Naizzara Rodríguez **
}

\section{RESUMEN}

Partiendo del supuesto que las subjetividades no son estructuras fijas temporales, sino, por el contrario, agentes movedizos que se reestructuran, redefinen, reactualizan y reacondicionan en las dinámicas del tiempo y el espacio como ha quedado demostrado desde mayo de 1968, tras la revolución cultural que colocó de presente el carácter cultural en el cual se construye y se sustentan las sociedades, nuestra propuesta de investigación "Análisis Sociocultural de la Violencia Intrafamiliar en Cartagena desde el relato del o la Hablante. Un Estudio de Género", se permitió deconstruir las relaciones conflictivas de la familia cartagenera (hombre, mujer, niñas, niños), definidas por patrones, modelos, conductas y códigos culturales que justifican los distintos roles de las subjetividades masculinas y femeninas en lo que se observa contradicción e inflexibilidad a partir de la socialización de géneros.

La investigación realizada cuestiona los paradigmas familiares existentes en Cartagena, que ponen en evidencia una constante lucha entre el poder y el contrapoder, el orden y el desorden expresados en el golpe, el maltrato y el insulto, que en algunos casos termina con la eliminación del otro u otra.

\section{Violencia Intrafamiliar y Subjetividades}

La investigación "Análisis Sociocultural de la Violencia Intrafamiliar en Cartagena desde el relato del o la Hablante. Un Estudio de Género", indagó la problemática a partir de las valoraciones y características culturales que sustentan el problema en el espacio privado y público, a través del estudio discursivo de las denuncias escritas presentadas por mujeres y hombres que reposan en las Comisarías de Familia, los Juzgados de Familia, la Casa de la Justicia y las dependencias del Instituto Colombiano de Bienestar Familiar en los períodos 1.999-2.000, y en el primer semestre del 2.001.

La violencia intrafamiliar presenta una tendencia histórica en Colombia, que se

${ }^{*}$ Este artículo es producto de la investigación: Análisis Sociocultural de la Violencia Intrafamiliar en Cartagena. Desde el Relato del o la Denunciante. Un Estudio de Género. Facultad de Ciencias Sociales y Educación. Este texto fue presentado en la conferencia nacional contra la violencia intrafamiliar, el 25 de Noviembre de 2004 en Barranquilla programada por el Alto Comisionado de Las Naciones Unidas para los Refugiados (ACNUR).

** Otros miembros del Equipo de Investigación: Rafael Acevedo (Historiador), Martisela Bermúdez (Trabajadora Social), Germán Betancourt (Historiador), Milton Buelvas (Abogado), David Lara Ramos (Abogado y Comunicador Social) 
ha venido complejizando a partir de la década de los 90' cuando se promulga la ley 294 de 1996 y posteriormente la 575 de 2000, estas reglamentaciones socio jurídicas contemplan el intervensionismo del Estado colombiano en la esfera privada del grupo principal de referencia social, en materia de familia uno de los logros más significativos en el Siglo XX.

En Cartagena los testimonios encontrados a través de la investigación develan toda una serie de estrategias de sujección al espacio del hogar, en el que el poder dominante del marido sobre la mujer materializa una lógica de subordinación. El hombre ha creído que tiene el derecho primario de controlar, disciplinar con severidad e incluso abusar de la vida de la mujer y los hijos.

La violencia intrafamiliar en Cartagena es un problema que tiene una carga valorativa desde la cultura, en gran medida porque la cultura presupone contradicciones y las sociedades no son estáticas sino cambiantes. La violencia no es sólo contra la pareja sino contra los niños y los colaterales del grupo familiar y tiene que ver con la atención de las instituciones, por ello, la formación de unas actitudes de aguante, de sufrimiento de silencio, subyacen en una valoración social del papel de la mujer y con la lógica que el Estado interviene a través de los instrumentos legales establecidos para estudiar el problema, de ahí que la violencia no es un problema privado, sino que hace parte de la salud pública, y compete al Estado su intervención.

Estudiar los procesos de construcción de las subjetividades permitió develar las mentalidades y los poderes imperceptibles que legitiman la violencia intrafamiliar en Cartagena, un tema en apariencia trivilalizado e investigado desde las instituciones del Estado, que lo han subestimado por décadas como un fenómeno de la causalidad, argumentando que la violencia se deriva de la drogadicción, del alcohol y de la tendencia oficial de la estadística. Desde la perspectiva de las instituciones públicas se concibe el tema como un asunto marginal, sinónimo de pobreza y de miseria. En este sentido, los grupos sociales de estratos altos quedaban al margen, como si estuviesen exentos de una "enfermedad o patología social". Visión que se cuestionó desde los resultados de esta investigación; pues los registros y subregistros encontrados en la Comisaría de Familia que recepciona los casos de los estratos 4, 5 y 6 son significativamente altos, ello quiere decir que el problema no se puede comprender como sinónimo de marginalidad.

La violencia se repite como hecho violatorio del ejercicio de la libertad a través del pensamiento y el ejercicio diario de imaginarios socioculturales esclavizantes que sustentan la cultura y la sociedad. Los imaginarios colectivos se transfieren 
a cuadros de amor y lealtad en donde las/os que se hallan en indefensión están atrapados y atrapadas sin salida, porque la salida debería centrarse en un reconocimiento del dispositivo cultural en el pensamiento que diariamente se repite en la cotidianidad, la ejemplificación del poder institucional del Estado contextualizado en la familia. El hombre, "el macho de la familia" cumple funciones aprendidas de los poderes institucionales de la sociedad, ejerce el control mediante la violencia física y psicológica al grupo familiar, en las relaciones afectivas, y un control social tradicional de dependencia económica, que ya no es una atadura prioritaria en la sociedad contemporánea, porque el capitalismo necesitaba en el Siglo XX no sólo del trabajo del hombre sino de los dos géneros, y los sistemas democráticos necesitaban de los votos de las mujeres.

La violencia intrafamiliar es una manifestación cultural aprendida, y en la familia se sustentan poderes que la legitiman, desde el sentido de propiedad del otro y la otra, y no como sujeto de libre decisión. En ese sentido los hijos son propiedad del padre y de la madre, la mujer es propiedad del marido y por ello pueden hacer lo que quieran con los niñas/os y la mujer. Esta forma de relaciones humanas estriba en el abuso, la agresión, y la polarización de las interacciones, que convierten a las partes en extremos confrontados en forma desventajosa debido a la subordinación y a los valores que la privilegian.

Sin embargo, el hecho de que en 1998 se sobrepasaron las 3.000 denuncias y el número ascendió en 1999, y en el período 2000 - 2002, hace saber que hay una resistencia de parte de los y las violentadas, que la violencia ha llegado al límite de lo inadmisible. Se está gestando en las familias cartageneras un desafío al poder hegemónico del imaginario social aprendido, las denuncias constituyen ya una ganancia, se está gestando un contrapoder elaborado desde el daño psicosocial del maltrato que de alguna manera se verá referenciado como venganzas, aún cuando las instituciones no sepan que hacer con éstas.

La violencia intrafamiliar en Cartagena se dirige hacia las cosas-objetos de la casa- en primera instancia, luego hacia la pareja con aumento del abuso verbal y del abuso físico. "Todo lo partió, los vidrios de los cuadros que adornaban el salón donde me desempeño como agente educativa, no quiere que trabaje". ${ }^{1}$ Son múltiples las razones sociales, económicas, culturales, religiosas, legales y/o financieras que mantienen a las mujeres dentro de una relación familiar violenta; en particular unas ataduras que simbolizan los afectos, la dependencia económica -que no es de tipo económico en los estratos 4, 5 y 6; en estos se deriva de las mentalidades aprendidas a través de la cultura, la valoración del status social, el apellido "prestante" y los privilegios materiales que brinda la

\footnotetext{
1 Los relatos de las denuncias provienen de los 7 Juzgados de Familia de Cartagena, las Comisarías de Familia y los Centros de Conciliación y del ICBF.
} 
pertenencia a una familia de "clase", la participación en un club social "elitista". Todo ello se conjuga en una masculinidad ortodoxa e inflexible, que se representa a través del poder en el imaginario de la feminidad, que impide el desarrollo de la autonomía y las decisiones libres.

"Cada vez que salgo me intrata de palabras diciéndome que soy una perra, una puta, una zorra (...) me maltrató en todo el cuerpo. Él dice que si yo lo dejo me va a quitar a mis hijos", "El señor me amenazó con que me iba a matar y me iba a quitar los niños y me agarró por el cabello, todo sucede porque yo no quiero vivir más con él". Las amenazas de quitar a los hijos son un constante mecanismo de violencia hacia la pareja, hacen parte de los abusos psicológicos contra la mujer y los hijos. Los menores de edad entran en el círculo de la manipulación de los adultos muchas veces sin que estos observen el malestar psicológico de los niños.

"Mi marido me golpea por cualquier motivo, me ofende de palabra, si le pido algo para los niños, para que me lo de es un problema, una vez haciendo aseo le quité unas cuñas a la cama y se me olvidó colocárselas y por eso me dio una trompada mientras yo dormía. Ahora me echó de la casa porque le estaba echando unas gotas medicinales en los ojos y le cayó a fuera y enseguida me dio patadas y me tuve que ir de la casa".

Los agresores cartageneros trasladan habitualmente el maltrato que han acumulado en otros ámbitos (en el trabajo o con los amigos) a la familia "hoy mi marido en las horas de la mañana me dio un garrotazo por la pierna y cada vez que está arrebatado me pega cuando le da la gana; me dio bien duro con un palo, esto pasa cada vez que pierde el Júnior". La necesidad de descargar las tensiones acumuladas por sucesos frustrantes se asocian a la violencia intrafamiliar, el cuerpo de la mujer y los hijos son utilizados como instrumentos de regulación del ego masculino.

El poder ejercido del hombre hacia la mujer muestra unas dinámicas relacionales de polarización de los géneros que se representan en la acción de la violencia. La violencia en este caso se convierte en un mecanismo de poder, amparado por unos imaginarios socioculturales de sujeción, reproducidos de manera simbólica por una idea histórica de dominio. Lo que el relato de la hablante muestra es la trasgresión a los marcos normativos impuestos por la racionalidad patriarcal, la acción de desafío a esta liturgia masculina al tomar una decisión: "pero yo fui", esboza una dinámica de resistencia al poder, desafiando una "ley" simbólica fabricada por el saber popular que dice: "que las mujeres serias no van a fiestas". Las violaciones a los cánones establecidos o impuestos revelan un 
castigo por la falta cometida, ya no contra la figura del individuo "ofendido" por la omisión a su advertencia, que en este caso se convierte en una ley: "tú eres arrestada te dije que no vinieras y viniste", si no, por atentar contra un principio reproducido por un aprendizaje cultural que subraya que, "los hombres se respetan".

Al desconocer la lógica normativa masculina, amparada en un derecho al respeto, sustentado por la cultura, se establece toda una economía del castigo para corregir al sujeto "desviado", representado aquí por una mujer irrespetuosa que no obedece las ordenes que se le imponen. Los golpes, las marcas en el cuerpo, van acompañados por una justificación de la pena "que esto es (era) para que sea seria y aprenda a respetar" son una multiplicidad de estrategias punitivas, en términos foucaultianos formas de teatralizar el poder, ${ }^{2}$ toda una dinámica del control que descalifica a la mujer-sujeto de derecho por la insurrección a un saber. El desacato al poder de normalización formulado por una idea del poder dominante que la circunscribe a un espacio específico de circulación, "te dije que te quedaras en casa, allí es donde debes estar", justifica un conjunto de técnicas y procedimientos empleados para el enderezamiento de quienes se resisten a la domesticación, una máquina de captura para los sujetos que trastocan el orden establecido, es una serie de procesos que tiene como objetivo "poner en su sitio" a la infractora que representa formas simbólicas de ser en el mundo, perpetuadas por unos códigos culturales, que identifican a la mujer en un espacio determinado.

\section{Feminidades y Masculinidades en la Construcción de Subjetividades Familiares}

Las subjetividades familiares son un campo simbólico construido por los discursos moralizantes a través de la apropiación cultural, que se saturan cuando se evidencia la inequidad y el abuso del poder, el castigo y la violencia, dejando en duda así el supuesto idealista según el cual la familia es una institución de valores para dar lugar al espacio de poderes mediante el cumplimiento de las normas en el hogar, como lo analizó el equipo de investigación en los numerosos casos sobre violencia intrafamiliar presentes en Cartagena al final del milenio.

Desde esta perspectiva se observa que la concepción ideológica de la familia nuclear, ha promovido valores hegemónicos en la construcción de las subjetividades de hombres y mujeres. Si bien es cierto, que el término familia va mas allá de lo que es el núcleo, y de lo que se trata es de interpretar las lógicas familiares desde el punto de vista del concepto, queda claro que las familias son

${ }^{2}$ FOUCAULT, Michel. Vigilar y Castigar, Editorial siglo XXI, México 1984. Pg 14-45 


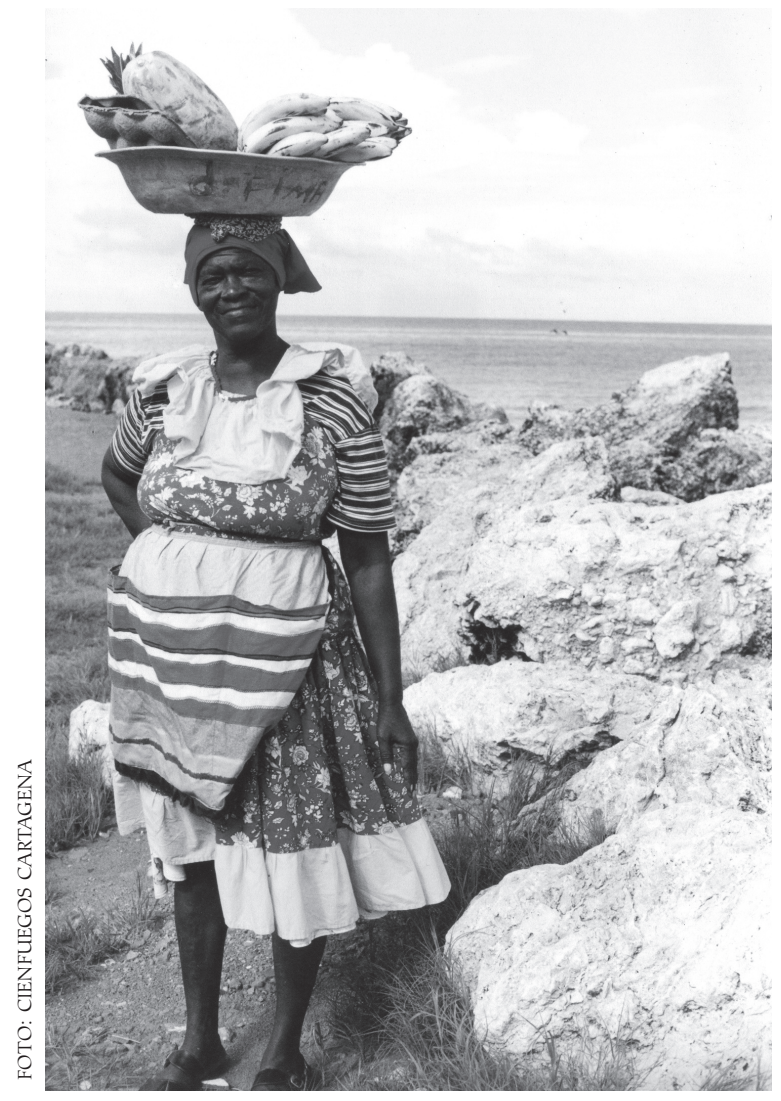

cambiantes y mantienen una relación con las distintas estancias de poder que representa el Estado, visto de esta manera las familias son microespacios en donde se legitiman los mecanismos de poder y representación de la lógica del Estado; es preciso aclarar que en Cartagena no predomina una tipología de familia nuclear, sino que se evidencia una tendencia más amplia, las familia extensas o de redes de apoyoen particular para los sectores populares- como lo identifican algunos investigadores entre quienes se destacan Pablo Rodríguez y Claudia Mosquera, entonces es válido pensar que la construcción de subjetividades se produce en ambientes de socialización diferentes, las familias, las escuelas y las comunidades y alejados de las simbologías identitarias de la familia nuclear.

El enfoque del tipo ideal de familia y los roles inscritos en la teoría funcionalista posibilitan tensiones y conflictos, ${ }^{3}$ pues no hay familias ideales, las familias existen como tales porque existe una lógica cultural y socioeconómica. En Cartagena no se percibe la familia como un núcleo sino como un grupo social heterogéneo, una institución de poder en la que conviven personas con múltiples y disímiles intereses, en la vida cotidiana se manifiestan conflictos entre los que se destacan aquellos derivados de la violencia de géneros. Por otra parte, las subjetividades entran en conflicto con los supuestos de la modernidad cuyas implicaciones representan la participación de la gente en la vida cotidiana de Cartagena, en los espacios públicos y políticos de toma de decisiones y en la cosmovisión del mundo de hombres y mujeres.

En las relaciones de género, las denuncias muestran una carga semántica del dolor y un lenguaje que moldea la personalidad de los actores en conflicto, que incorporan a su vida una manera de entender los conflictos, de soslayarlos, de olvidarlos en virtud de la socialización de géneros. En esa socialización hay unos

${ }^{3}$ Según los críticos del funcionalismo este no representa las diferentes lógicas de interpretación de la familia, diseñada para una sociedad pragmática, de alguna manera para "un mundo feliz". herederos del honor y de la autonomía, y otras/os heredan la atención, la paciencia y la obediencia.

El conflicto en principio está dado por la construcción cultural de la familia anclada en valores, y códigos hegemónicos con una división de roles tajante que no se relaciona con los cambios sociales que impone la modernidad. A partir 
de la tradición el deber ser de la mujer la conmina a la obediencia de los poderes institucionales: la familia, la religión, el Estado, el marido y todos los patrones valorativos de la racionalidad patriarcal. La obediencia se instaura como ritual y subyace en el imaginario colectivo, en la vida cotidiana, en la repetición mecánica de los mismos actos, en la disposición de espacios, horarios y rutinas.

La obediencia se realiza en detrimento del libre ejercicio del pensamiento. En este sentido la obediencia es sinónimo de esclavitud y como tal en ningún tiempo produce personas autónomas; la obediencia tampoco ha producido ciencia, arte o desarrollo, la ciencia y el conocimiento se producen por la desobediencia a los cánones y por las motivaciones de la creatividad; por el contrario los regímenes autoritarios y excluyentes no producen pensamiento libre. ${ }^{4}$

La mayoría de los autores (Weber, 1.969, Simmel, 1.977, Arenndt, 1.970, Foucoult, 1.988, Litk, 1.992) están de acuerdo, en que el poder no es un estado sino una relación que se materializa por la imposición de la voluntad de uno sobre otras/os; la distribución del poder en la familia se da entre la reproducción de los bienes económicos, el trabajo productivo, el uso del tiempo libre, las responsabilidades.

El ejercicio del poder como legado en la cultura cartagenera es de carácter androcentrico y masculinizante en la dimensión de la vida cotidiana. Aún se concibe la participación en la vida política como un sinónimo del rol masculino diferente al de las mujeres que están marcados por su mayor participación en la familia.

Esta práctica de poder tiene tres espacios diferentes de socialización en la cultura cartagenera, en la vida cotidiana, en las interacciones sociales y como estrategia política y de violencia. En este sentido, el poder es una realización en la que median las individualidades, la sexualidad y las identidades. Una dimensión que ofrece cambios y transiciones a medias, que se materializan en la vida productiva y en la limitada participación política de la mujer cartagenera.

${ }^{4}$ RODRÍGUEZ Hortensia Naizara. La Violencia Intrafamiliar en

Estas formas dominantes de las masculinidades contemporáneas en Cartagena se reproducen en el interior del espacio familiar, en el que las normas, las reglas y los deberes son impuestos por el pensamiento patriarcal en torno a los roles de la feminidad, que al transgredirse producen unas relaciones violentas que deterioran la integridad humana.

Cartagena, Develando el Imaginario de la Masculinidad y la Feminidad. Palobra No. 3. Facultad de Ciencias Sociales y Educación Universidad de Cartagena. 2002. 
Estas creencias conservadoras referencian y legitiman unas prácticas sociales en las que unos se identifican como víctimas y otros como victimarios; así se definen las relaciones hombre - mujer violentada. Se continúa con las mentalidades que los hombres son malos y peligrosos y las mujeres frágiles, débiles, menores de edad y en algunos casos minusválidas. El asunto va más allá de la peligrosidad, porque se trata de la cosmovisión del mundo, del alma masculina y del alma femenina.

Una de las razones más comunes que sustenta la violencia intrafamiliar en Cartagena, es el poder que ejercen los hombres sobre la sexualidad de las esposas o cónyuges; pareciera que este poder no tuviese límites, porque son frecuentes las golpizas, los insultos degradantes, cuando las mujeres no acceden o presentan disculpas ante las urgencias masculinas. Violaciones, acoso sexual, vejaciones, golpes en el rostro y humillaciones verbales son consentidas y toleradas cotidianamente por las mujeres; interesa pensar entonces en lo que sucede al interior de la psiquis femenina y masculina, pues las mujeres conviven con muchos miedos ancestrales y se hallan atrapadas en traumas emocionales, que no les permiten tomar decisiones. Las violaciones son ejercidas por los cónyuges, y sólo hasta la década de los sesenta las cortes empezaron a aceptar la eventual existencia de la violación por el cónyuge.

Los cuerpos femeninos sometidos históricamente por la cultura, las religiones y el Estado se convierten en un campo de batalla político, en los que confluyen múltiples fuerzas, estas se simbolizan, a través de los criterios de verdad los cuales dan la imagen de sexualidades buenas y malas; constituidas a través de dispositivos de normalización que crean la noción del poder y control sobre la sexualidad y desviación. Por ello, se explica el código cultural aprendido: el cuerpo de la mujer es interpretado como posesión indefinida por parte del marido aunque estén separados, el hombre se asume como dueño del cuerpo de la otra, es así como el sentido de la posesión física posibilita la construcción de identidades femeninas en Cartagena y subjetividades sometidas a dispositivos de dominación, no sólo del marido sino de las instituciones.

Las mujeres cartageneras reaccionan muy lentamente en la búsqueda de su propia defensa, en parte porque las acosa un terrible sentimiento de culpabilidad administrado y dosificado por la cultura, culpabilidad que las atormenta y sencillamente las pone al servicio de los demás, olvidándose de sí mismas y de su propia autorrealización. De otra parte las mujeres no tienen información precisa y detallada sobre los derechos que le son vulnerados en los eventos de violencia 
en el grupo familiar, esto aún cuando algunas de ellas hayan incursionado en el espacio público, con la vinculación a las universidades, a los medios productivos, a la representación política.

Las mujeres en Cartagena afrontan desventajosamente a su violentador, desde su posición de debilidad se identifican con la figura de víctima, el punto central es la fuerza masculina versus la indefensión femenina. Las mujeres cargan con los fracasos de todos y sienten poco apoyo de su grupo inmediato, asimismo de las instituciones y de los mecanismos jurídicos que existen para su protección porque no funcionan adecuadamente, también por el dominio ideológico cultural que pesa sobre sus conciencias, que les hacen temer hasta de sí mismas. Confinadas en medio de tantos temores difícilmente construyen su propio proyecto de vida.

El ámbito doméstico en Cartagena es determinado por relaciones de mando autoritario, en el cual emergen normas y leyes culturales de dominación, regulación y control del padre sobre el resto del núcleo familiar, cuya misión principal es salvaguardar "la constitución del pensamiento humano" según la cual el hombre es el jefe de hogar y la mujer y los menores los guardianes de él. Esta justificación ideológica no coincide con la realidad social de las/los cartageneros, que en gran medida tienen hogares con jefatura femenina.

El imaginario de autoridad patriarcal y las estrategias de control en las familias cartageneras son un proceso selectivo de enseñanza de los códigos culturales de masculinización y feminización a través de objetos simbólicos y discursos que muestran el "ser hombre y ser mujer". En muchos casos los parámetros de la educación familiar se definen a partir de modelos pedagógicos de violencia intrafamiliar práctico y no mediante discursos que sustenten nuevos roles en las relaciones de género.

Los valores socioculturales en Cartagena que se sustentan en la familia y legitiman la violencia, tienen múltiples formas de manifestaciones: verbales y de coacción psicológica, como expresiones de ataque al cuerpo femenino y el cuerpo de las niñas/os. En los relatos se encontraron marcadores lingüísticos, frases claves, repetitivas que dan cuenta de valores y prejuicios aprendidos que objetivizan el control del otro y la otra,

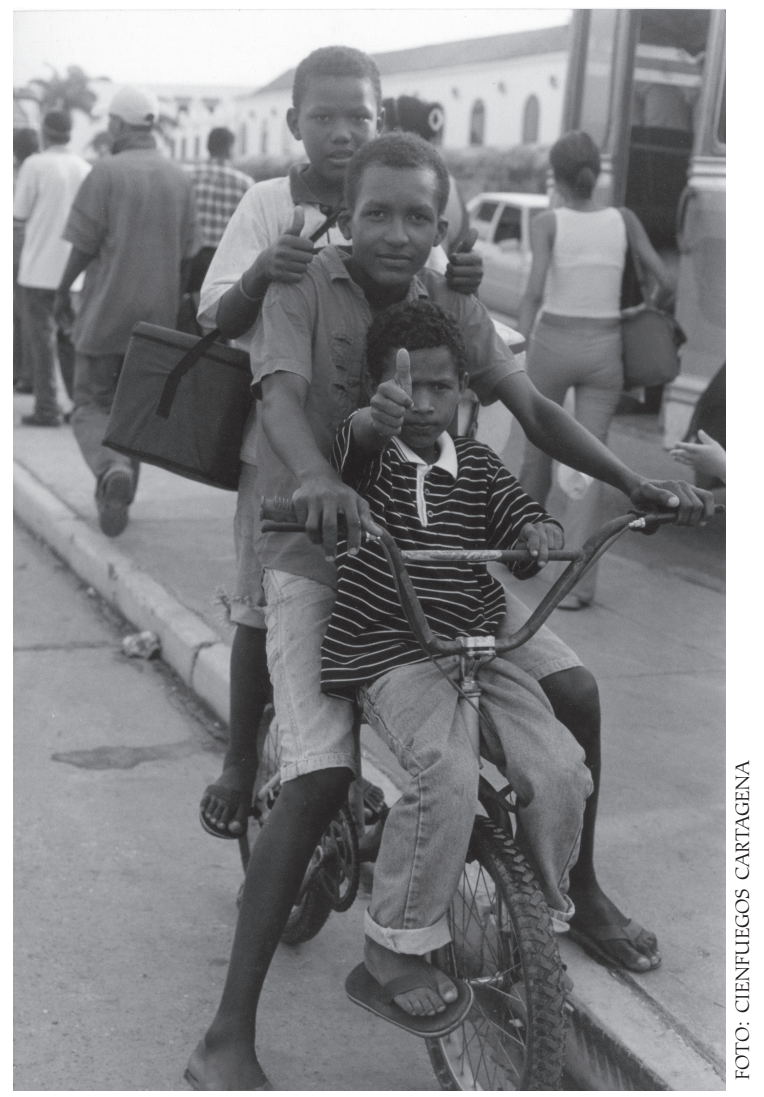


lo mismo que la culpabilización y el sentido de la justicia mediante el uso del cuerpo como un instrumento de poder y control.

Los imaginarios sociales de la feminidad como ser que ama el amor, y guardadora del hogar, y de la masculinidad como el ser de los placeres y de la fortaleza, se complementan con la división de roles específicos en el trabajo; a las mujeres se les enseña desde temprana edad a laborar en la casa, pues la misión asignada por la cultura es procrear niños, alimentarlos y educarlos, mientras el hombre cumple una función instrumental por fuera del hogar para proveer económicamente a la familia. De tal sentido que la imagen masculina se encuentra en gran medida separada de los lazos afectivos hacia los hijos/as, y lo femenino es la expresión afectiva que trata de orientar a las mujeres en el hogar. Estos imaginarios se encuentran en conflicto, porque encontramos a muchos hombres aprendiendo nuevas valoraciones del afecto hacia los hijos/as y sus familias. La pervivencia de estos imaginarios es producto de las normas culturales, de la dinámica de la sociedad y la familia contemporánea, de los logros de la modernidad, y del capitalismo.

\section{"Yo Soy el que los Mantiene"}

Como atributo de las masculinidades la proveeduría económica presupone a los hombres como jefes del hogar con todos los derechos sobre los miembros del grupo familiar. La dependencia económica de la mujer y los hijos justifican cualquier forma de violencia del hombre en la familia. "X pretende que como su papá nos está manteniendo tengo que vivir con él por regla”. La relación económica desigual se constituye en un objeto de dominación.

En el marco de los relatos del dolor, el imaginario sociocultural cartagenero define a la "mujer sana" en al ámbito doméstico, como sumisa y obligada a estar en la casa, a ocuparse de la atención del marido y los hijos, sin derecho a la expresión y a las interacciones sociales fuera del hogar "en las reuniones no me deja hablar, dice que yo no tengo derecho a hablar" de esta manera se vulnera la incorporación de la mujer en el contexto extra familiar, minimizando las posibilidades de acceso a los dispositivos de bienestar de orden político, económico y tecnológico necesarios para visibilizar procesos de empoderamiento femenino.

La vinculación de la mujer cartagenera a la vida productiva le posibilita romper con la dominación hegemónica violenta, "Yo no quiero vivir mas con él porque yo trabajo y no lo necesito". Los procesos de exclusión de la mujer del ámbito doméstico a la inclusión productiva laboral del escenario público, han engendrado 
un desequilibrio en las relaciones de géneros, suscitando una redistribución del poder sobre los usos de los bienes financieros e intelectuales que intervienen en las actividades productivas.

\section{"Yo le Pego con Razón"}

En la socialización de géneros en Cartagena se presenta una marcada diferenciación entre la conformación de las masculinidades y las feminidades, excluyentes y tajantes, sustentadas en la creencia tradicional en que la razón es sinónimo de fuerza y justifica la aplicación de la misma; entre los textos leídos alcanzamos a comprender la categoría de la racionalidad, en las frases repetitivas "yo tengo la razón", "es que yo tengo la razón" o "ella es una perra" o "el salió para el perreo" Configuran estos códigos un práctica cotidiana de la violencia y el maltrato físico y verbal, a través del uso de un lenguaje ofensivo y de la práctica cotidiana del golpe. Imponer la razón a través de la fuerza no sólo ha sido un asunto cotidiano sino un ejercicio de tácticas políticas, de violencia social; se observan unas estrategias de poder y dominación, que excluye a la mujer cartagenera de apreciarse a sí misma como un ser que toma decisiones propias, aún se le trata como un ser débil que se debe a la obediencia que se manifiesta en la dinámica de las familias, en las instituciones sociales, establecidos en el modelo de masculinidades hegemónicas que promueve la inequidad de género.

Dentro de las valoraciones socioculturales de los cartageneros, se ubica al hombre como el juez que dicta sentencia contra el comportamiento femenino a través del golpe y la represión "No encontraba comida se puso rabioso y me golpeó porque yo era una buena para nada", El imaginario sociocultural de la masculinidad apoya la creencia del hombre como refinador de la personalidad de la mujer, el que corrige los defectos "Todos los diez y siete años que he vivido con ella es corrigiéndole tantos defectos".

\section{"Para que me Respete"}

Entre las estructuras discursivas masculinas de poder se relieva la utilización de la coacción física como medio de reivindicacación y aseguramiento de la dignidad del hombre "Yo la agarré por el pelo y le di unas trompadas para que me respete". El uso del poder hegemónico androcéntrico utiliza las diversas formas de violencia para reafirmar el respeto que deben darle los miembros del grupo familiar "Que no me moleste más que no se le olvide que yo soy un hombre", esta idea de respeto a los hombres es sinónimo de obediencia. A los hombres se respeta, a las mujeres no. El hombre siempre recuerda que es hombre la mujer no. 
5 Juzgado Primero de Familia .Caso registrado el 21 de Abril de 1998
"Nos invitaron a una fiesta el sábado donde unos amigos, y el decidió ir solo, porque él dice que las mujeres serias no van a fiestas, pero yo fui y cuando me vio me dijo: "tú eres arrestada te dije que no vinieras y viniste, te dije que te quedaras en casa, ahí es donde debes estar". Cuando llegamos y ahí fue cuando me levantó a golpes por la cabeza y trataba de sacarme los ojos, entonces me agredió con una botella, y me cortó por la cara y si no meto el brazo me saca los ojos, cuando me pegaba me decía: "que esto era para que sea seria y aprenda a respetar, me dijo que me iba a poner en mi sitio que lo respetara porque los hombres se respetan" me pegó duro por todo el cuerpo tengo un poco de verdes que me salieron, mire como me dejó". ${ }^{5}$

En los casos estudiados se evidencia un asunto bastante subjetivo y muy importante desde la perspectiva de los valores y las libertades, es el valor de la dignidad y el buen nombre lo que vale la pena entender e interpretar; como se aprecian estos desde la masculinidad del hombre cartagenero, es lo que se observa en el siguiente texto:

"La perseguí para pegarle y enseñarle que a los hombres se respeta, a cualquier hombre que le falten a su dignidad responde de esta manera, porque no es posible que mientras uno está trabajando y luchando para darle todos los gustos a ella y a nuestros hijos, como es la buena educación y el deporte, donde me tocaba escaparme del trabajo para llevarlos a las prácticas de béisbol, ella salía con sus amigas lo mismo que ella de cachonas a entregarse a otros hombres y cortaba la plata de la comida para comprarse ropa, donde no había necesidad, pero todo con el fin de pantallear, como será que era tanta ropa la que tenía, que le regalaba a sus amigas alcahuetas. Yo creo y estoy seguro que llegó hasta el colmo de pagar la salida y darle regalos a sus amantes, regalando hasta flores, ya que a los dos meses de haberme abandonado con los dos niños, llamaron por teléfono cobrando un saldo que había dejado en la floristería, o sea que me tenía de paganini, también se me llevó unos jeans y una ropa y yo creyendo que era una mujer sana, que había ido al pueblo a encontrarse con Dios, a encontrarse con ella misma y que sólo para darme un escarmiento, pero una cuñada, del mismo pueblo me dijo que estaba viviendo con su amante, cuando me enteré de eso, yo quise ponerle una demanda por hurto, me dijeron aquí en el juzgado que había caducado, si no estuviera encarcelada. Una mujer que abandona a sus hijos es una mujer desnaturalizada y enferma, pero como las leyes protegen tanto a estas mujeres infieles por eso abandonan a sus maridos y a sus hijos, dejando a los niños al albedrío y los maridos con el corazón destrozado y por eso están los templos evangélicos llenos, menos mal que uno busca a Dios, de lo contrario estuviéramos en las cárceles o locos como muchos. Yo no pienso matarla, yo no soy bruto para pasar en la cárcel el resto de mis días, tengo la responsabilidad de educar a mis hijos, pero estas mujeres se merecen una limpia, ella fue la que cogió el cuchillo, 
ella es una mujer peligrosa, ya que cuando vivíamos ella me partió el ojo y tengo una cicatriz de 4 puntos. Además compré un revolver para seguridad de la casa y una vez lo cogió para matarme. Yo sólo quiero desenmascararla y agradezco a Dios que se haya ido, porque una mujer y con tantos defectos; ya en la policía tiene una demanda por estafa y falsificación de seguros escolares. Ella no puede tener los niños porque le gusta el enchunche con homosexuales y lesbianas, los echaba de la casa y cuando me iba para el trabajo nuevamente los metía, no me tenía ni pizca de respeto y esta clase de gente da mal ejemplo para sus hijos. Ella no trabaja en Sincelejo y cuando trabajaba, pensando que va a ayudar en el hogar salía cara porque había que comprarle ropa, y nunca metió un peso, y todos los 17 años que he vivido con ella fue corrigiéndole tantos defectos, lo que traía era buen cacho, ella vive en San Andrés de Sotavento con el tipo en una finca en zona de guerrilla y paramilitares; todo lo que habla por su boca es pura mentira, parece un angelito pero hay que recordar que el diablo se viste de ángel, y de pronto no es culpa de ella ser así, sino que viene de la familia, les gusta ser libres, no tener compromisos con nada, ni con los hijos."

A Manera de Conclusión

Considerar a las mujeres como seres débiles es una falacia de la cultura y de las mentalidades que concibieron el destino del Estado y la sociedad; es un vicio de la sociedad feudal ancestral y esclavista que aún no hemos podido superar. En Colombia no hay esclavitud desde José Hilario López; pero aún pervive un imaginario y una mentalidad ancestral. En particular en la Cartagena del siglo XXI sigue siendo una dimensión colectiva del pensamiento, la discriminación social a mujeres, negras/os, discapacitados y en general a todos aquellos que no están en condiciones de defender sus derechos, y esto por desconocimiento, desinformación y temores que se plasman en los diferentes contextos sociales. Los cambios cualitativos en la construcción de nuevas subjetividades en las relaciones no violentas entre hombres y mujeres, es necesario impulsarlos a través de investigaciones y proyectos educativos que lleguen a las comunidades y a todos los estratos sociales.

\section{BIBLIOGRAFÍA}

ARANGO, Luz Gabriela y Otras. Género E Identidad. Ensayos Sobre Lo Femenino Y Lo Masculino. Tercer Mundo Editores. Año 1.995.

ARIAS, Melba. Cinco Formas de Violencia Contra La Mujer. Ediciones Ecoe. Santafé De Bogotá. 1991.

Palobra No. 6 Agosto/2005 
FOUCAULT, Michel. Vigilar y Castigar, Editorial siglo XXI, México 1984.PG 14-45

GUTIÉRREZ de Pineda, Viginia. La Familia en Colombia, Trasfondo Histórico. Editorial Universidad de Antioquia, Ministerio de Cultura. Medellín, Antioquia. 1997.

PROFAMILIA. Violencia Contra la Mujer y los Niños en Colombia. Fondo de Publicación de Naciones Unidas. Año 1.995.

VILLEGAS Escobar, Juan Camilo. Imaginario Social. Editorial Eafit, Medellín 1980.

BIOGRAFÍA
HORTENSIA NAIZZARA RODRÍGUEZ

Trabajadora Social Universidad de Cartagena, Magíster en Proyectos de Desarrollo Social Universidad del Norte, Docente de la Facultad de Ciencias Sociales y Educación. 